\title{
Literatur
}

1. Heilmeyer, L. und K. Plötner, Das Serumeisen und die Eisenmangelkrankheit. Gustav Fischer, Jena (1937). - 2. DAvis, A. E. und J. BEDENoch, Lancet (London) II, 6 (1962). - 3. SCHROEDER, H. A., Advances Int. Med. (N. Y.) 8, 259 (1956). - 4. WolfF, H. P., Klin. Wschr. 34, 409 (1956). - Wolfr, H. P., Verh. Dtsch. Ges. inn. Med. 70, 338 (1964). - 6. VALLEE, B. L. und J. H. R. KÄGI, Schweiz. med. Wschr. 88, 132 (1958). - 7. LAiNGE, J., Verh. Dtsch. Ges. inn. Med. 70, 330 (1964). - 8. SchäFER, K. H., Verh. Dtsch. Ges. inn. Med. 70, 262 (1964). - 9. Pferlsticker, K., diese Z. 3, 145 (1965). - 10. Pferlsticker, K., Angew. Chem. 65, 244 (1953). - 11. Pfeilsticker, K., Mikrochim. Acta (Wien, 319 (1956). - 12. Kaiser, H., Spectrochim. Acta (Roma) 3, 297 (1947). - 13. Karser, H., Spectrochim. Acta (Roma) 4, 351 (1951). 14. SAIDEL, A. N., W. K. Prokofjew und S. M. RaIskr, Spektraltabellen. VEB Volk und Gesundheit, Berlin (1955). - 15. GLEU, K. und R. SchwaB, Angew. Chem. 62, 320 (1950). - 16. WILK, G., Unveröffentlichter Erfahrungsbericht vom 10. 3. 1965. - 17. Bersin, Th., Biochemie der Mineral- und Spurenelemente. Akademische Verlagsellschaft, Frankfurt/Main (1963). - 18. Carlberger, G., G. Magnusson und L. Meurmann, Acta med. Scand. 170, 479 (1961). - 19. Horst, W. und H. H. Schumacher, Klin. Wschr. 49, 361 (1954). - 20. WIBERG, G. S., I. C. MunRo und A. B. Morrison, Canad. J. Biochem. 45, 1219 (1967). - 21. Cluetr, M. L. und J. H. Yoe, Analytic. Chem. 29, 1265 (1957). -
22. Imbus, H. R., J. Cholak, L.-H. Miller und T. Sterling, Arch. environm. Hlth. 6, 286 (1963). - 23. Schroeder, H. A. und H. M. Perry jr., J. Laborat. Clin. Med. (S. Louis) 46, 936 (1955). - 24. Schroeder, H. A. und W. H. Vinton jr., Amer. J. Physiol. 202, 515 (1962). - 25. Schrozder, H. A., Amer. J. Physiol. 207, 62 (1964). - 26. Yunice, A. und H. M. Perry jr., J. Laborat. Clin. Med. (S. Louis) 58, 975 (1961). - 27. Carrold, R. E., J. Amer. Med. Ass. 198, 267 (1966). - 28. KäGr, J. H. R. und B. L. VALLEE, J. biol. Chemistry 235, 3460 (1960). - 29. KäGr, J. H. R. und B. L. VALLEE, J. biol. Chemistry 236, 2435 (1961). - 30. VANDER, A. J., Amer. J. Physiol. 203, 1 (1962). - 31. VANDer, A. J., Amer. J. Physiol. 203, 1005 (1962). - 32. Monacell, R., J. Tanaka und J. H. YoE, Clin. chim. Acta (Amsterdam) 1, 577 (1956). - 33. Curran, G. L., J. biol. Chemistry 210, 765 (1954). - Mertz, W., E. E. Roginski und K. Schwarz, J. biol. Chemistry 236, 318 (1961). - 35. Roginskr, E. E. und W. Mertz, Federation Proc. 24, 510 (1965). - 36. Bowen, H. J. M., Internat. J. Appl. Radiat. Isotopes 5, 227 (1959). - 37. Papavasiliou, P. S. und G. C. Cotzias, J. biol. Chemistry 236, 2365 (1961). - 38. Cotzias, G. C., Verh. Dtsch. Ges. inn. Med. 70, 327 (1964). - 39. Casirola, G. und L. Petronio, Arch. sc. biol. (Bologna) 42, 572 (1958). - 40. Hedge, B., G. C. Griffith und E. M. Butr, Proc. Soc. exp. Biol. Med. 107, 734 (1961).
Prof. Dr. D. P. Mertz Med. Univ. Poliklinik 78 Freiburg i. Brsg. Hermann-Herder-Str. 6

\section{Atomabsorptionsspektrometrische Cadmiumbestimmung in Serum und Harn}

\author{
Von G. Lehnert, K. H. Schaller und Th. HaAs \\ Aus dem Institut für Arbeits- und Sozial-Medizin der Universität Erlangen-Nürnberg \\ (Direktor: Prof. Dr. H. Valentin)
}

(Eingegangen am 30. Juli 1967)

\begin{abstract}
Die angegebene Methode mit atomabsorptionsspektrometrischer Endpunktbestimmung etlaubt eine quantitative Cd(II)-Analyse in biologischem Material. Sie schließt Veraschung und Extraktion des Metalls in ein organisches Lösungsmittel nach Chelatbildung ein. Zuverlässigkeitskriterien des Verfahrens werden mitgeteilt. Cadmium-Analysen bei beruflich nicht exponierten Erwachsenen ergaben im Serum eine Cd (II)-Konzentration von $0,33 \pm 0,24 \mu \mathrm{g} / 100 \mathrm{~m} l$ und im Harn eine tägliche Cd(II)-Ausscheidung von $0,98 \pm 0,36 \mu \mathrm{g}$.
\end{abstract}

A method for the quantitative analysis of $\mathrm{Cd}$ (II) in biological material is reported, in which the end point is determined by atomic absorption spectrophotometry. The material is ashed and the metal, in the form of a chelate, is extracted into an organic solvent. Criteria for the reliability of the method are given. Cadmium analyses on occupationally non-exposed adults gave Cd(II) concentrations of 0.33 $\pm 0.24 \mu \mathrm{g} / 100 \mathrm{~m} l$ serum and a daily urinary $\mathrm{Cd}(\mathrm{II})$ excretion of $0.98 \pm 0.36 \mu \mathrm{g}$.

Cadmium ist bei seiner Verwendung im industriellen Arbeitsprozeß wegen seiner akut oder chronisch-kumulativ toxischen Wirkungen arbeitsmedizinisch von großer Bedeutung. Am Arbeitsplatz etwa bei der Herstellung von Legierungen, Akkumulatoren oder Farbstoffen durch Inhalation inkorporiert, findet sich Cd(II) hauptsächlich in Lungen, Leber, Herz und Nieren. Die Dekorporation des Metalls erfolgt in Harn und Stuhl.

Nach Trpton (1) reichert sich Cd(II) im Organismus auch unter normalen Bedingungen im Laufe des Lebens an, wobei etwa $30 \%$ der gesamten Cd(II)-Last in den Nieren akkumuliert werden. SCHRöDER (2) und Mitarbeiter gelangten aufgrund tierexperimenteller $\mathrm{Er}$ gebnisse und umfangreicher Untersuchungen am Menschen zu dem Schluß, daß zwischen dem Cd(II)-Gehalt der Nieren und gewissen Formen der arteriellen Hyper- tonie eine Beziehung besteht. Unter diesen Aspekten ist $\mathrm{Cd}$ (II) nicht nur von arbeitsmedizinischem, sondern von allgemein-medizinischem Interesse.

In dieser Situation scheint eine Verfeinerung und Vereinfachung der Analysenmethoden für Cd(II) im Serum und Harn wünschenswert. In hohem Maße erfüllt diese Forderung ein von uns entwickeltes atomabsorptionsspektrometrisches Bestimmungsverfahren. Die hier mitgeteilten Ergebnisse beziehen sich ausschließlich auf beruflich nicht $\mathrm{Cd}$ (II)-exponierte Erwachsene, über gewerbetoxikologische Untersuchungen werden wir an anderer Stelle berichten.

Die direkte quantitative Bestimmung . von Cd(II) im Normalurin und Normalserum ist mit handelsüblichen Atomabsorptionsspektrometern nicht möglich. Nur durch Einsatz empfindlichkeitssteigernder Absorptions- 
röhren, wie sie Pulido, Fưwa und Vallee (3) benutzen, ist die Analyse ohne vorangehende chemische Aufarbeitung durchführbar.

In Analogie zu anderen Metallbestimmungen (4) läßt sich die Verwendung eines derartigen Zusatzgerätes durch Umsetzung mit einem Chelatbildner und Extraktion in ein organisches Lösungsmittel umgehen.

Die Extraktion in ein kleines Volumen gestattet eine erhebliche Anreicherung des Metalls; zusätzlich verbessert das organische Lösungsmittel die atomare $\mathrm{Ab}$ sorption etwa um das Doppelte. Ein weiterer Vorzug des organischen Mediums ist die Eliminierung von Fehlern infolge unterschiedlicher physikalischer Eigenschaften der Proben. Viskositätsunterschiede und „Light scattering "-Effekte') lassen sich auf diese Weise umgehen. So verändern für $\mathrm{Cd}$ (II) auch große Mengen von komplex gebundenen Schwermetallen $(250 \mathrm{mg} \mathrm{Fe} / 100 \mathrm{ml}$ organisches Lösungsmittel) die atomare Absorption nicht.

Als Chelatbildner wurde von uns Ammoniumpyrrolidindithiocarbamat, zur Extraktion Methylisobutylketon verwendet. Die Komplexbildung von $\mathrm{Cd}(\mathrm{II}) \mathrm{mit}$ Ammoniumpyrrolidindithiocarbamat erfolgt vollständig in einem Bereich von $\mathrm{pH} 2$ bis $\mathrm{pH} 3$ (Abb. 1); die Extraktion des gebildeten Chelats in Methylisobutylketon verläuft ebenfalls vollständig, da sich im wäßrigen Rückstand kein Cd(II) mehr nachweisen läßt.

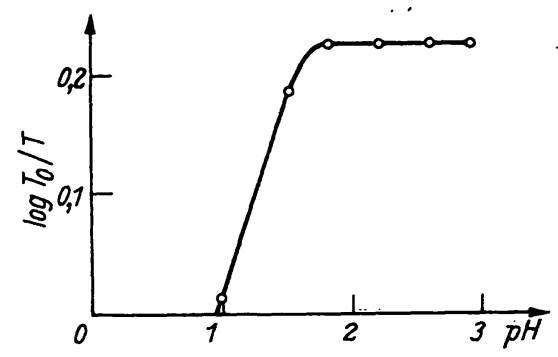

Abb. 1

Abhängigkeit der Cd(II)-Chelatbildung mit Ammoniumpyrrolidindithiocarbamat vom $\mathrm{pH}$-Wert

Es ist noch nicht genau bekannt, in welcher Form Cd(II) im Urin und Serum vorliegt, und damit unsicher, ob ohne vorherige Veraschung der Probe eine vollständige Chelatbilduing stattfindet. Wir führen deshalb eine nasse Veraschung des Ausgangsmaterials durch.

\section{Methode}

Wie bei allen Spurenelementanalysen wird von Reagenzien und verwendetem Glasmaterial höchster Reinheitşrad verlangt. Dies gilt auch für Probenentnahme und -sammlung.

Zur Bestimmung im Serum werden $10 \mathrm{ml}$ Serum mit $10 \mathrm{~m} l$ 65proz. $\mathrm{HNO}_{3}, 5 \mathrm{ml}$ 96proz. $\mathrm{H}_{2} \mathrm{SO}_{4}$ und $5 \mathrm{ml} 70$ proz. $\mathrm{HClO}_{4}$ verascht. Nach Bedarf wird weitere $\mathrm{HClO}_{4}$ hinzugegeben. Zur Bestimmung im Urin werden $50 \mathrm{~m} /$ Urin bis zur Trockene eingedaimpft und mit $10 \mathrm{ml} \mathrm{HNO}_{3}, 5 \mathrm{~m} / \mathrm{H}_{2} \mathrm{SO}_{4}$ und $5 \mathrm{ml} \mathrm{HClO}_{4}$ vetascht. Der weiße Veraschungsrückstand wird in verdünnter Salzsäure aufgenommen, am pH-Meter auf $\mathrm{pH}$ 2,5 eingestellt und im Scheidetrichter mit $2 \mathrm{ml} 5$ proz. wäßr. Ammoniumpyrrolidin-

1) Fremdabsorptionen aufgrund der Anwesenheit von soliden Salzpartikeln innerhalb der Flamme. WirLrs (5) erklärt damit seine hohen $\mathrm{Cd}(\mathrm{II})$-Werte im Urin $(0,05 \mathrm{mg} / \mathrm{l})$.
dithiocarbamat-Lösung und $2 \mathrm{ml}$ Methylisobutylketon versetzt. Man schüttelt $2 \mathrm{Min}$. und trennt die organische Phase, mit der die atomabsorptionsspektrometrische Messung erfolgt, ab.

Als Atomabsorptionsspektrometer wurde von uns das Gerät der Firma Beckman, ausgerüstet mit einem 'Turbulenzbrenner, in Kombination mit dem Spektralphotometer DU verwendet.

\section{Apparative Arbeitsbedingungen}

Cd-Hohlkathodenlampe ( $\mathrm{Fa}$. Westinghouse Electric Corp.) Stromstärke $5 \mathrm{~mA}, 3$ Brenndüsen, Flamme dreifach durchstrahlt, Luftdruck $11 \mathrm{psi}$, Wasserstoffdruck $2 \mathrm{psi}$, Spaltbreite $0,06 \mathrm{~mm}$, Wellenlänge $2288 \AA$, Schreiber: 10 Zoll Recorder, Fa. Beckman.

Zur Gewinnung einer Eichleurve ist eine Veraschung der $\mathrm{Cd}$ (II)Standardlösungen nicht obligat. Es genügt eine direkte Extraktion dieser Lösungen, wenn man einen Veraschungsleerwert mitberücksichtigt. Abbildung 2 zeigt zwei Eichkurven, die durch Veraschung bzw. durch direkte Extraktion der Proben gewonnen wurden. Die Absorptionsdifferenz zwischen beiden Kurven entspricht genau dem gemessenen Leerwert $\left(\log T_{0} / T=0,020\right)$.

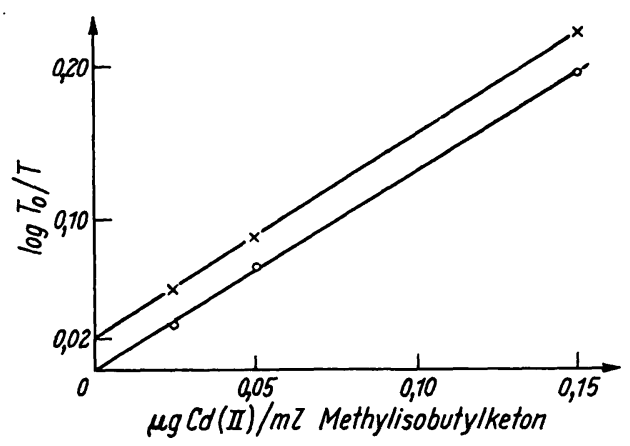

Abb. 2

Eichkurve für die atomabsorptionsspektrometrische Messung von Cd(II).

$x-x$ Veraschung der Proben

- 0 Extraktion der Proben ohne Veraschung

Unter optimalen Meßbedingungen kann im organischen Medium eine Nacbweisgrenze (bezogen auf $1 \%$ Absorption) von $0,003 \mu \mathrm{g} / \mathrm{m} /$ Methylisobutylketon erreicht werden. Die Nachweisgrenze im wäßr. Medium beträgt $0,007 \mu \mathrm{g} / \mathrm{ml}$.

Bei der von uns verwendeten Volumenrelation zwischen Ausgangsmaterial $(50 \mathrm{~m} l \mathrm{Harn}, 10 \mathrm{~m} l$ Serum) und Extraktionsmittel $(2 \mathrm{~m} l$ Methylisobutylketon) sind im Urin noch Konzentrationen von $0,012 \mu \mathrm{g} / 100 \mathrm{ml}$, im Serum von $0,06 \mu \mathrm{g} / 100 \mathrm{ml}$ Cd(II) nachweisbar. Zur Uberprüfung der Reproduzierbarkeit ergab die 6fache Bestimmung eines Urins einen mittleren $\mathrm{Cd}(\mathrm{II})-$ Gehalt von $0,053 \pm$ $0,005 \mu \mathrm{g} / 100 \mathrm{ml}(\mathrm{VK}= \pm 10 \%)$.

Die mittlere Wiederauffindungsrate betrug, nach Zusatz von $0,1 \mu \mathrm{g}$ Cd(II) zu $10 \mathrm{ml}$ Serum mit einem Cd(II)-Gehalt von $0,67 \mu \mathrm{g} /$ $100 \mathrm{ml}, 96 \%$ (Tab. 1 ).

Tab. 1

Wiederauffindung

\begin{tabular}{cccc}
\hline Probe & $\log \mathrm{T}_{0} / \mathrm{T}^{\text {Serum }+0,1 \mu \mathrm{g} \mathrm{Cd}(\mathrm{II})}$ & $\begin{array}{c}\text { Wiederauffindung } \\
\text { gefunden }[\mu \mathrm{g} \text { Cd(II) }(\mathrm{II})]\end{array}$ \\
\hline 1 & 0,092 & 0,166 & 0,099 \\
2 & 0,093 & 0,167 & 0,100 \\
3 & 0,087 & 0,157 & 0,090 \\
\hline Mittelwert & 0,091 & 0,163 & 0,096 \\
\hline
\end{tabular}

\section{Ergebnisse}

Untersucht wurden Serum und Harn von jeweils 15 beruflich nicht Cd(II)-exponierten Erwachsenen. Dabei ergab sich ein mittlerer Cd(II)-Gehalt des Serums von $0,33 \pm 0,24 \mu \mathrm{g} / 100 \mathrm{~m} l$ und eine durchschnittliche Ausscheidung von $0,98 \pm 0,36 \mu \mathrm{g} \mathrm{Cd}(\mathrm{II})$ im 24 Stdn.-Urin (Tab. 2). 
Tab. 2

Cd(II)-Werte im Serum und Uri Serum- und Urin-Werte stammen nicht vom gleichen Probanden

\begin{tabular}{cccc}
\hline Nr. & $\begin{array}{c}\text { Serum } \\
{[\mu \mathrm{g} 100 \mathrm{~m} l \mathrm{Cd}(\mathrm{II})]}\end{array}$ & $\begin{array}{c}\text { Urin } \\
{[\mu \mathrm{g} \mathrm{Cd}(\mathrm{II}) / \mathrm{Tag}]}\end{array}$ & $\begin{array}{c}\text { Urinmenge } \\
{[\mathrm{m} l]}\end{array}$ \\
\hline 1 & 0,24 & 0,73 & 2200 \\
2 & 0,32 & 1,26 & 870 \\
3 & 0,16 & 1,34 & 1200 \\
4 & 0,47 & 1,57 & 1800 \\
5 & 0,16 & 0,34 & 800 \\
6 & 0,22 & 0,58 & 730 \\
7 & 0,23 & 0,77 & 1200 \\
8 & 0,25 & 0,54 & 850 \\
9 & 0,40 & 1,07 & 1920 \\
10 & 0,92 & 1,02 & 1455 \\
11 & 0,12 & 1,25 & 1120 \\
12 & 0,90 & 0,57 & 1250 \\
13 & 0,18 & 0,99 & 1270 \\
14 & 0,22 & 1,33 & 940 \\
15 & 0,18 & 1,31 &
\end{tabular}

Wir konnten somit die von Burt (6) gemessenen hohen $\mathrm{Cd}(\mathrm{II})$-Werte im Serum $(40 \mu \mathrm{g} / 100 \mathrm{~m} /)$ nicht bestätigen. Die Angaben von KLaus (7) $(4 \mu \mathrm{g} / 100 \mathrm{~m} /)$ und Pulido und Mitarbeiter (3) $(1 \mu \mathrm{g} / 100 \mathrm{ml})$ beziehen sich nur auf Einzelproben.

Die Werte unserer Harnanalysen stimmen etwa mit denen spektrographisch von IMBUS (8) ermittelten überein $(1,15 \mu \mathrm{g} / D)$; sie liegen aber wesentlich unter denen von Pulido (3), Klaus (7), Smith (9) sowie Perry und Perry (10). Angesichts der stark wechselnden Harntagesmengen erscheinen uns die Angaben als Konzentrationen unzweckmäßig. Wir beziehen deshalb die Cd(II)-Ausscheidung auf den 24-Stdn.-Urin.

\title{
Literatur
}

1. Tipton, J. H., in: Metall-Binding in Medicine, S. 27, hrsg. von M. J. Seven, J. B. Lippincott Co., Philadelphia (1960). - 2. Schroeder, H. A., J. chron. Dis. 18, 647 (1965). - 3. Pulido, P., K. Fuwa und B. L. VAlleE, Analyt. Biochem. (New York) 14, 393 (1966). - 4. Lehnert, G., und K. H. Schaller, Med. Welt 18, 1131 (1967). - 5. WiLlis, J. B., Analytic. Chem. 34, 614 (1962).
- 6. Burt, E. M., Arch. Environ. Health 8, 60 (1964). - 7 . Klaus, R., diese Z. 4, 299 (1966). - 8. Imbus, H. R., Arch. Environ. Health 6, 112 (1963). - 9. Smrth, J. C. und J. E. KeNCH, Brit. J. industr. Med. 14, 240 (1957). - 10. PerRY, H. M. jr. und E. F. PerRy, J. Clin. Invest. 38, 1452 (1959).

Dr. med: G. Lehnert

852 Erlangen, Schillerstr. 25

\section{Photometrische Mikromethode für die komplexometrische Titration von Calcium}

\author{
Von R. Quicker und H.-J. Dulce \\ Aus dem Institut für Angewandte Pbysiologische Chemie und Klinische Chemie der Freien Universität Berlin
}

(Direktor: Prof. Dr. H.-J. Dulce)

(Eingegangen am 19. Mai 1967)

Es wird eine automatische Calciumtitration mit Äthylendiamintetraessigsäure (EDTA) und Ammoniumpurpurat als Indikator in stark alkalischem Medium für einen Bereich von 2-15 $\mu \mathrm{g}$ Calcium pro Ansatz angegeben. Der maximale Fehler der Einzelbestimmung beträgt $0,13 \mu \mathrm{g}$, der mittlere Fehler im Bereich von 6-15 $\mu \mathrm{g}$ Calcium pro Ansatz etwa 1,5\%.

A method is reported for the automatic titration of calcium with ethylenediaminetetraacetic acid (EDTA) and ammonium purpurate as indicator in strongly alkaline medium. The concentration range is 2-15 $\mu \mathrm{g}$ calcium per sample. The maximum error of a single determination is $0.13 \mu \mathrm{g}$; the average error in the range $6-15 \mu \mathrm{g}$ calcium per sample is about $1.5 \%$.

Die manganometrische Bestimmung des Calciums nach Fällung als Oxalat (1) war früher die Standardmethode für die Untersuchungen in biologischen Flüssigkeiten, erforderte aber größere Serummengen und sorgfältiges Arbeiten. Sie wurde abgelöst durch die komplexometrische Methode nach SchwarzenBach (2) und Ellrotr (3). Die Schwierigkeit dieser Methode ist die exakte Endpunktbestimmung.

Fales (4), Kibrick (5) und Siegmund und Dulce (6) erarbeiteten deshalb eine Mikromethode für die komplexometrische Bestimmung mit $0,1 \mathrm{~m} l$ Untersuchungslösung und photometrischer Endpunktanzeige. Für Serienbestimmungen ist sie geeignet. Es müssen aber die Titrationen von Hand erfolgen und zur Ermittlung der Äquivalenzpunkte Titrationskurven gezeichnet werden. Wir haben jetzt für diese Mikromethode die Titration und Meßwertregistrierung automatisiert. Weiterhin wurde die Methode durch Stabilisierung des Indikators und Anwendung magnetischer Rührung verbessert. COpp (7) hat kürzlich eine ähnliche Mikromethode.für
Calciumbestimmungen angegeben, bei der das Mischen mit einem normalen Rührer vorgenommen wurde. Dies hat den Nachteil, daß die Oberfläche der Lösung nicht ruhig bleibt, die Photometeranzeige schwankt und die automatische Registrierung ungenau wird.

\section{Methodik}

Prinzip

Calciummurexid (rot) besitzt im stark alkalischen Medium $\mathrm{pH}>12$ eine vom freien Murexid (blauviolett) unterschiedliche Farbe. Der Aquivalenzpunkt der Titration ist visuell schlecht, photometrisch gut bestimmbar $(8,9,10)$.

Die Absorptionsspektren von Murexid und seinem Calciumchelat (molare Extinktion $\varepsilon\left(\mathrm{cm}^{2} / \mathrm{Mol}\right)$ als Funktion von $\lambda$ aufgetragen) zeigt Abbildung 1 (nach 10).

Die Differenz der Absorptionswerte erreicht bei 480 und $570 \mathrm{~nm}$ ihr Maximum. Der Wellenlängenbereich um 480 und $570 \mathrm{~nm}$ ist deshalb für die photometrische Endpunktbestimmung besonders geeignet.

Für eine scharfe Endpunktsbestimmung sind nach Forturs und Mitarbeitern (11) noch folgende Bedingungen entscheidend: 